\title{
L-Proline and L-Pipecolate Induce Enkephalin-Sensitive Currents in Human Embryonic Kidney 293 Cells Transfected with the High-Affinity Mammalian Brain L-Proline Transporter
}

\author{
Aurelio Galli, ${ }^{2}$ Lankupalle D. Jayanthi, ${ }^{1}$ I. Scott Ramsey, ${ }^{1}$ Joshua W. Miller, ${ }^{3}$ Robert T. Fremeau Jr, ${ }^{3}$ and \\ Louis J. DeFelice ${ }^{1}$ \\ ${ }^{1}$ Department of Pharmacology and Center for Molecular Neuroscience, Vanderbilt University Medical Center, Nashville, \\ Tennessee 37232-6600, '2Department of Pharmacology, University of Texas, Health Science Center, San Antonio, Texas \\ 78284-7764, and ${ }^{3}$ Department of Pharmacology and Cancer Biology and Neurobiology, Duke University Medical Center, \\ Durham, North Carolina 27710
}

The high-affinity mammalian brain L-proline transporter (PROT) belongs to the GAT1 gene family, which includes $\mathrm{Na}$ - and $\mathrm{Cl}$-dependent plasma membrane carriers for neurotransmitters, osmolites, and metabolites. These transporters couple substrate flux to transmembrane electrochemical gradients, particularly the Na gradient. In the nervous system, transporters clear synapses and help to replenish transmitters in nerve terminals. The localization of PROT to specific excitatory terminals in rat forebrain suggests a role for this carrier in excitatory transmission (Renick et al., 1999). We investigated the voltage regulation and electrogenicity of this novel transporter, using human embryonic kidney (HEK) 293 cells stably transfected with rat PROT cDNA. In physiological solutions between -140 and $-40 \mathrm{mV}$, L-proline (PRO) and its six-member ring congener L-pipecolate (PIP) induced inward current. The current-voltage relationship and the variance of current fluctuations were similar for PROand PIP-induced current, and the ratio of induced variance to the mean current ranged from 20 to $60 \mathrm{fA}$. Des-Tyr-Leuenkephalin (GGFL), a competitive peptide inhibitor of PROT, reduced the rat $P R O T-a s s o c i a t e d$ current to control levels. GGFL alone did not elicit currents, and the GGFL-sensitive substrate-induced current was absent in nontransfected cells. Finally, GGFL inhibited PROT-mediated transport only when applied to the extracellular face of PROT. These data suggest that (1) PROT uptake is electrogenic, (2) individual transporter currents are voltage-independent, and (3) GGFL is a nonsubstrate inhibitor that interacts either with an extracellular domain of PROT or in an externally accessible pore.

Key words: proline; pipecolic acid; transporter; enkephalin; voltage-clamp; uptake; current; HEK-293 cells
A mammalian brain high-affinity L-proline transporter (PROT) was cloned from a rat forebrain cDNA library on the basis of amino acid sequence conservation between GABA and norepinephrine transporters (Fremeau et al., 1992). The PROT cDNA encodes a $68 \mathrm{kDa}$ glycosylated protein that exhibits $42-50 \%$ amino acid sequence identity with a gene family of $\mathrm{Na}-$ and Cl-dependent plasma membrane transports proteins that mediate high-affinity uptake of neurotransmitters (norepinephrine, dopamine, serotonin, GABA, glycine), osmolites (taurine, betaine), and the metabolite creatine (Shafqat et al., 1993; Velaz-Faircloth et al., 1995; Miller et al., 1997a,b). These transporters use transmembrane electrochemical gradients to transport substrates across the plasma membrane. They are also critical targets for therapeutic and pathological alterations of synaptic function (for review, see Kanner, 1989; Amara and Kuhar, 1993; Rudnick and Clark, 1993; Blakely et al., 1994; Lester et al., 1994). The brain-specific expression of PROT in human (Shafqat et al., 1995) and rat (Velaz-Faircloth et al., 1995) tissues is consistent

\footnotetext{
Received Sept. 15, 1998; revised May 13, 1999; accepted May 14, 1999.

This work was supported by a National Alliance for Research on Schizophrenia and Depression Young Investigator Award (A.G.) and National Institutes of Health Grants NS-33373 (L.J.D.) and NS-32501 (R.T.F.). We thank Dr. Barbara Domin for her assistance in generating the HP-21 cell line and Dawn Borromeo for her invaluable help in maintaining cell lines, preparing solutions, and other technical assistance.

Correspondence should be addressed to Dr. Louis J. DeFelice, Department of Pharmacology, Vanderbilt University Medical Center, Nashville, TN 37232-6600. Copyright (C) 1999 Society for Neuroscience $0270-6474 / 99 / 196290-08 \$ 05.00 / 0$
}

with a unique physiological role for this transporter in the mammalian CNS.

The pharmacological specificity, ion dependence, and kinetics of the cloned transporter expressed in non-neural cells (Fremeau et al., 1992, 1996; Shafqat et al., 1995) are similar to the corresponding properties of the high-affinity component of synaptosomal L-proline uptake (Bennett et al., 1972; Peterson and Raghupathy, 1972; Balcar et al., 1976; Nadler, 1987). These properties distinguish PROT from the other widely expressed Na-dependent plasma membrane carriers that transport L-proline (PRO), including the intestinal brush border "imino" carrier (Stevens et al., 1984) and the system "A" and system "ASC" neutral amino acid carriers (Christensen, 1990). In situ hybridization of rat brain sections and cultured hippocampal neurons demonstrated that PROT mRNA is expressed by subpopulations of putative glutamatergic neurons in rat brain (Fremeau et al., 1992; VelazFaircloth et al., 1995). Recently, Crump et al. (1999) observed that the PROT protein is localized to a subset of excitatory terminals in cultured rat hippocampal neurons. Furthermore, ultrastructural studies showed that PROT is localized selectively to a subset of presynaptic axon terminals, forming asymmetric excitatory-type synapses typical of glutamatergic synapses (Renick et al., 1999). These findings raise the possibility of a specialized role for PROT and its presumed natural substrate, L-proline, in the modulation of excitatory synaptic transmission in specific excitatory pathways within the CNS. High-affinity L-proline uptake may regulate the ability of extracellular proline 
to potentiate excitatory transmission at those synapses that express PROT (Cohen and Nadler, 1997).

To gain biophysical insight into the nature of PROT-mediated transport processes, we established the cell line HP-21 by stably transfecting human embryonic kidney 293 (HEK-293) cells with rat PROT cDNA (Fremeau et al., 1992). The HP-21 cell line is suitable for biochemical analysis, radiolabeled flux studies, and patch-clamp recording techniques. Electrophysiological measurements reveal that rat PROT (rPROT) is electrogenic; however, individual transporter events are not voltage-dependent. We also suggest that several previously identified inhibitors of high-affinity L-proline uptake, including L-pipecolate (PIP), an endogenous brain L-lysine metabolite (for review, see Giacobini et al., 1980), are likely PROT substrates, and we propose a Na- and Cldependent stoichiometric mechanism for PRO and PIP transport. Finally, we demonstrate that the competitive peptide inhibitor Des-Tyr-Leu-enkephalin (GGFL) inhibits PROT-mediated transport processes only from the outside.

\section{MATERIALS AND METHODS}

rPROT stable cell lines and tissue culture. An Eco RI/XbaI fragment of the rat PROT cDNA containing the entire protein coding sequence was released from pBluescript $\mathrm{KSII}^{-}$) (Fremeau et al., 1992) and subcloned into EcoRI/XbaI-digested pcDNA3 (Invitrogen, San Diego, CA) such that PROT expression was under the control of enhancer-promoter sequences from the immediate-early gene of the human cytomegalovirus (CMV). To generate stably transfected cell lines, we transfected the pcDNA3-PROT mammalian expression construct by calcium phosphate coprecipitation (Invitrogen) into HEK-293 cells at $\sim 50 \%$ confluence. The cells were cultured in DMEM supplemented with $10 \%$ heatinactivated fetal bovine serum and $50 \mu \mathrm{g} / \mathrm{ml}$ gentamycin. After $3 \mathrm{~d}$ the transfected cells were switched to medium containing $250 \mu \mathrm{g} / \mathrm{ml} \mathrm{Gene-}$ ticin (G418; Life Technologies, Gaithersburg, MD). Resistant colonies were isolated 2 weeks later by using sterile cloning rings, and individual resistant cells were used to generate clonal lines. Multiple lines exhibited GGFL-sensitive $\left[{ }^{3} \mathrm{H}\right]$-PRO uptake and immunoreactive PROT protein. Clonal line HP-21 was used in all of the experiments reported here. The culture of HEK-293 cells stably transfected with rat PROT cDNA (HP-21 cells) was as follows: HP-21 cells were cultured in DMEM supplemented with $10 \%$ fetal bovine serum, 2 mM L-glutamine, penicillin $(100 \mathrm{U} / \mathrm{ml})$, and streptomycin $(100 \mathrm{mg} / \mathrm{ml})$. Trypsin-released cells were seeded in 24-well cell culture plates at $1-1.5 \times 10^{5}$ cells/well and allowed to grow for $48 \mathrm{hr}$ before the transport measurements were done.

Transport assays. Measurements were performed in triplicate by incubating the HP-21 cells for $10 \mathrm{~min}$ at $37^{\circ} \mathrm{C}$, with $\left[{ }^{3} \mathrm{H}\right]-\mathrm{PRO}$ in $0.5 \mathrm{ml}$ of Krebs-Ringer's-HEPES-Tris (KRHT) buffer, $\mathrm{pH}$ 7.4, containing (in mM) $120 \mathrm{NaCl}, 4.7 \mathrm{KCl}, 2.2 \mathrm{CaCl}_{2}$, and $10 \mathrm{D}$-glucose. The concentration of HEPES was $10 \mathrm{mM}$, and the concentration of Tris was $5 \mathrm{~mm}$. For the time course of uptake, we used $50 \mathrm{~nm}\left[{ }^{3} \mathrm{H}\right]-\mathrm{PRO}$ to determine the incubation period for uptake $(10 \mathrm{~min})$. This introduces an approximation, because higher concentrations will fall off faster from their initial velocities. The consequence is to underestimate $V_{\max }$ by as much as $20 \%$. Thus we underestimated the coupled current.

Assays were terminated by removing the radiolabeled PRO and by washing the cells rapidly three times with $1 \mathrm{ml}$ of ice-cold KRHT buffer. Cells were solubilized with $1 \mathrm{ml}$ of Optiphase scintillant (Wallac, Gaithersburg, MD), and accumulated radioactivity was quantified by direct scintillation spectrometry with a Microbeta microplate scintillation counter (Wallac). Inhibitors were added $10 \mathrm{~min}$ before the addition of labeled substrates in the inhibition studies, whereas unlabeled substrates were added simultaneously with labeled substrates in the kinetic studies. The cells were counted each time just before the assay. Substrate $K_{\mathrm{m}}$ and $V_{\max }$ were determined by nonlinear least-square fits (Kaleidagraph, Synergy Software, Reading, PA) with the generalized Hill equation: $V=$ $V_{\max }[S]^{n} /\left(K_{\mathrm{m}}{ }^{n}+[S]^{n}\right)$, where $V$ is the transport velocity, $[S]$ is the substrate concentration, and $n$ is the Hill coefficient. Inhibitor $K_{\mathrm{i}}$ values were determined by nonlinear least-squares fits, using two-parameter logistic equations: the percentage of specific $\mathrm{PRO}$ transport remaining $=$ $100 /\left[1+\left(\mathrm{IC}_{50} /[I]\right)^{n}\right]$. The $\mathrm{IC}_{50}$ is the concentration of inhibitor giving $50 \%$ inhibition, $[I]$ is the inhibitor concentration, and $n$ is the slope (Hill coefficient). To determine $K_{\mathrm{i}}$ values, we adjusted $\mathrm{IC}_{50}$ values to account for substrate concentration (Cheng and Prusoff, 1973). Data are represented as the means \pm SEM of six independent measurements on three separate batches of cells. The dependence of $\left[{ }^{3} \mathrm{H}\right]-\mathrm{PRO}$ on $\mathrm{Na}$ and $\mathrm{Cl}$ concentration was determined by the method of Clark and Amara (1994). The ionic concentrations in KRHT buffers were varied by mixing the NaCl-containing buffer with those that lacked $\mathrm{Na}$ or $\mathrm{Cl}$. After $15 \mathrm{~min}$ preincubation, $\left[{ }^{3} \mathrm{H}\right]$-PRO $(0.05 \mathrm{ml})$ was added to each well $(50 \mathrm{~nm}$ final concentration). Transport in each well was stopped after $10 \mathrm{~min}$ by three $1 \mathrm{ml}$ washes with ice-cold KRHT solutions (without glucose) that contained the same $\mathrm{Na}$ and $\mathrm{Cl}$ concentration as during preincubation and transport. After the last wash, 1\% SDS was added to each well. After solubilization a small aliquot of each solubilized cell mixture was set aside for protein determination (Bio-Rad DC Protein Assay Kit, Richmond, CA). The rest was mixed with scintillation fluid for scintillation counting. We defined uptake into nontransfected HEK cells as background. Each assay was performed in triplicate, and mean specific uptake \pm SEM was determined and expressed as $\mathrm{pmol} / \mathrm{mg}$ protein per $10 \mathrm{~min}$.

Electrophysiology. Stably transfected cells have advantages for electrophysiology over transiently transfected cells. They express more uniformly, have more negative resting potentials $(-30$ to $-50 \mathrm{mV})$, and form tighter seals $(>20 \mathrm{G} \Omega$ ) for whole-cell voltage clamp than, for example, transiently transfected HeLa cells (Risso et al., 1996). Before electrical recording, parental or stably transfected cells were plated at a density of $10^{5}$ per $35 \mathrm{~mm}$ culture dish, and attached cells were washed three times with bath solution at room temperature. The normal bath contained (in mM): $130 \mathrm{NaCl}, 1.3 \mathrm{KCl}, 1.3 \mathrm{KH}_{2} \mathrm{PO}_{4}, 0.5 \mathrm{MgSO}_{2}, 1.5$ $\mathrm{CaCl}_{2}, 10 \mathrm{HEPES}$, and 34 dextrose. The solution was adjusted to $\mathrm{pH}$ 7.35 and $300 \mathrm{mOsm}$ with $1 \mathrm{~m} \mathrm{NaOH}$ and dextrose. Pipette solutions for the whole-cell recording contained (in $\mathrm{mm}$ ): $130 \mathrm{KCl}, 0.1 \mathrm{CaCl}_{2}, 2$ $\mathrm{MgCl}_{2}, 1.1$ EGTA, 10 HEPES, and 30 dextrose adjusted to $\mathrm{pH} 7.35$ and $270 \mathrm{mOsm}$. Free $\mathrm{Ca}$ in the pipette was calculated as $0.1 \mu \mathrm{M}$. To confirm specificity, we recorded substrate-induced currents in the absence and presence of GGFL. Electrodes were pulled with a Programmable puller (Sachs-Flaming, PC-84). An Axopatch 200A or EPC7 amplifier band limited at $5000 \mathrm{~Hz}$ was used to measure current. Series conductance was $0.1 \mu \mathrm{S}$ or greater, and cell capacitance was $25-80 \mathrm{pF}$, implying $2500-$ $8000 \mu \mathrm{m}^{2}$ surface area. HP-21 are clonal cell lines, and expression levels are constant to within a factor of two; however, with increasing passages there is decreasing expression. This prevented normalization of the current to surface area. Voltage steps ranged from -140 to $-20 \mathrm{mV}$ and lasted $500 \mathrm{msec}$. Test pulses were separated by $-20 \mathrm{mV}$ holding potentials for $4 \mathrm{sec}$. Values for steady-state currents were taken between 400 and $500 \mathrm{msec}$ after the step. Data were stored digitally on a VCR and analyzed on a Nicolet 4094 oscilloscope and an IBM-AT or Compaq Pentium computer, using instrumentation and programs written by W. N. Goolsby (Emory University, Atlanta, GA) or using pClamp 6.0.

\section{RESULTS}

Multiple colonies of rat PROT cDNA-transfected HEK-293 cells were isolated after Geneticin (G418) selection and assayed for GGFL-sensitive [ $\left.{ }^{3} \mathrm{H}\right]$-PRO uptake. One of these lines (HP-21) was expanded and analyzed for expression of PROT by immunolabeling, radiolabeled flux studies, and electrophysiological measurements. As documented in Renick et al. (1999), affinitypurified antipeptide antibodies directed against the $\mathrm{N}$ or $\mathrm{C}$ terminus of the rat PROT protein routinely recognize two specific immunoreactive bands on immunoblots of HP-21 membranes: an intense, broad immunoreactive band centered at $\sim 69 \mathrm{kDa}$ and a weaker immunoreactive band centered at $\sim 53 \mathrm{kDa}$. No specific labeling is observed in parental HEK membranes or when immunoblots are exposed to preimmune serum. Preabsorption of either antibody with the peptide used for its purification abolishes all immunolabeling (for a sample blot, see Renick et al., 1999). We previously observed that the anti-PROT antibodies recognize a single broad immunoreactive band centered at $\sim 68 \mathrm{kDa}$ on immunoblots of rat and human brain tissue (Shafqat et al., 1995; Velaz-Faircloth et al., 1995; Renick et al., 1999). Deglycosylation of rat brain membranes with PNGase F reduced the apparent molecular mass of the mammalian brain PROT protein from $\sim 68$ 
to $\sim 53 \mathrm{kDa}$, a size that corresponds to that of the primary PROT translation product determined by in vitro-coupled transcription and translation of the rat PROT cDNA in the absence of microsomes (Velaz-Faircloth et al., 1995; Renick et al., 1999). On the basis of these findings we conclude that the $\sim 69 \mathrm{kDA}$ band observed in HP-21 membranes represents the mature $\mathrm{N}$-glycosylated PROT protein, whereas the $\sim 53 \mathrm{kDa}$ band represents the unglycosylated primary translation product. Interestingly, although the apparent molecular mass of the major PROT immunoreactive band varies between experiments, depending on the percentage of acrylamide in the SDS-PAGE gel and the particular batch of molecular weight standards, a clear difference in electrophoretic mobilities is observed between PROTs expressed in HEK-293 stable transfectants (HP-21) and the immunoreactive rat brain PROT run side by side on the same $8 \%$ SDS-PAGE gel (Renick et al., 1999). These results suggest that the primary PROT translation product is subject to differential $\mathrm{N}$-glycosylation in HEK-293 cells versus rat brain.

\section{HP-21 cells transport proline}

HP-21 cells accumulated PRO in a time- and dose-dependent manner (Fig. 1). PRO uptake is approximately linear up to $20 \mathrm{~min}$ (Fig. 1A). To explore the functional properties of PROT, we performed kinetic analysis of $\left[{ }^{3} \mathrm{H}\right]$-PRO uptake. Nonlinear leastsquares curve fitting of saturation data was accomplished by using the generalized Hill equation (see Materials and Methods). Proline uptake follows saturable kinetics, with $K_{\mathrm{m}}=20.12 \pm 3.14 \mu \mathrm{M}$ and $V_{\max }=892.26 \pm 39.03 \mathrm{pmol} / 10^{5}$ cells per $10 \mathrm{~min}$ (Fig. $1 B$ ). The Eadie-Hofstee transformation yields a linear curve consistent with a single high-affinity interaction with an apparent $K_{\mathrm{m}}$ of $21 \mu \mathrm{M}$ (Fig. 1C). In contrast to the endogenous low-affinity PRO uptake observed in nontransfected HEK cells, which have a $K_{\mathrm{m}}$ of $\sim 350 \mu \mathrm{M}$ (Shafqat et al., 1995), HP-21 cells were capable of saturable uptake at low micromolar proline concentrations.

\section{Inhibition of L-proline uptake by leu-enkephalin and its des-tyrosyl derivative}

To characterize uptake, we tested the ability of unlabeled PRO and several structurally related compounds to compete for $\left[{ }^{3} \mathrm{H}\right]$ PRO uptake. Unlabeled PRO and its six-member ring congener, PIP, another possible substrate of PROT (Fremeau et al., 1992; Shafqat et al., 1995), produced a concentration-dependent reduction of $\left[{ }^{3} \mathrm{H}\right]$-PRO uptake in HP-21 cells. The apparent $K_{\mathrm{i}}$ values for these compounds were, respectively, $16.10 \pm 1.92$ and $17.44 \pm$ $1.58 \mu \mathrm{M}$ (Fig. 2). PROT exhibits significant amino acid sequence homology with other members of the GAT1 gene family but is unique in demonstrating a particular affinity for enkephalins. Fremeau et al. (1996) reported that leucine-enkephalin (YGGFL) and its des-tyrosyl derivative (GGFL) specifically inhibited highaffinity PRO uptake without affecting the plasma membrane transporter activity of several other members of the gene family. Here, we demonstrate that YGGFL and its des-tyrosyl derivative GGFL produced a concentration-dependent reduction of $\left[{ }^{3} \mathrm{H}\right]$ PRO uptake in HP-21 cells (Fig. 2). GGFL was more potent $\left(K_{\mathrm{i}}=3.51 \pm 0.67 \mu \mathrm{M}\right)$ than YGGFL $\left(K_{\mathrm{i}}=9.44 \pm 1.88 \mu \mathrm{M}\right)$ at inhibiting PRO uptake in the HP-21 cells.

\section{Ion dependence of $\left[{ }^{3} \mathrm{H}\right]$-L-proline uptake}

Isotonic substitution of extracellular $\mathrm{Na}$ ions with $\mathrm{Li}$ or extracellular $\mathrm{Cl}$ ions with isethionate abolished PRO uptake. This inhibition was reversible. In contrast, endogenous low-affinity transport of PRO is dependent on extracellular $\mathrm{Na}$, but not on extracellular Cl (Shafqat et al., 1995). Saturation curves for the
A

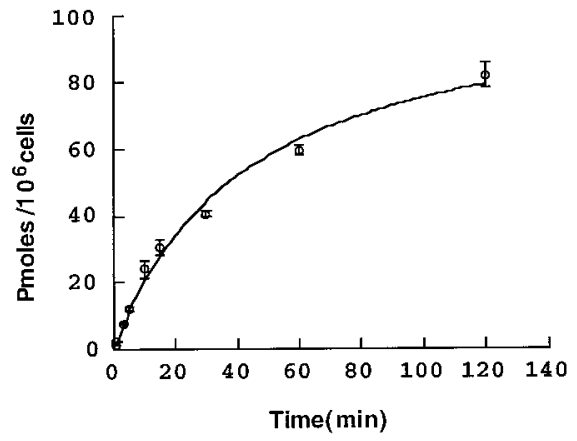

B

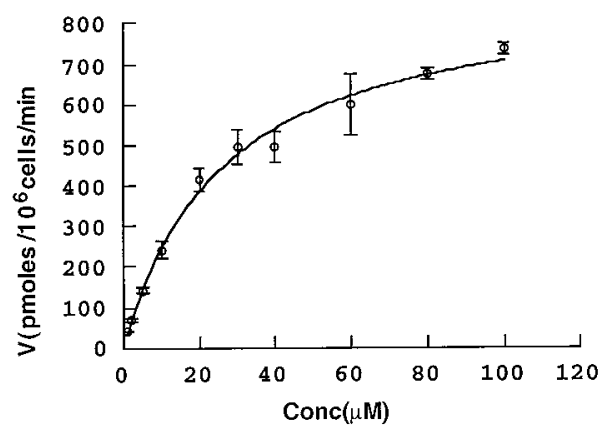

C

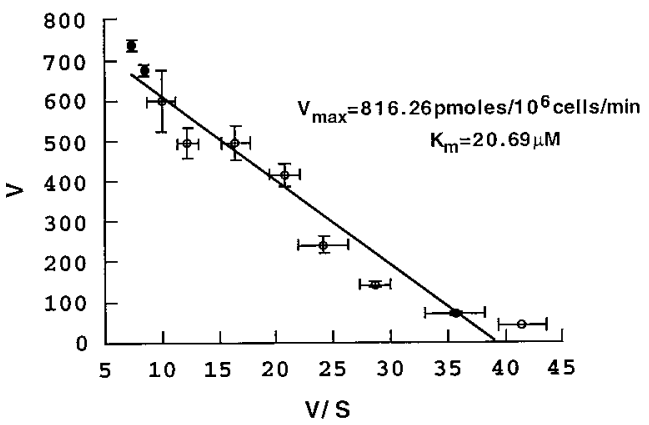

Figure 1. Characterization of proline transport. A, Time course of transport. HEK-293 cells stably transfected with rat PROT cDNA reveal time-dependent PRO uptake. Proline transport was assayed, as described in Materials and Methods, for increasing time periods, and the picomoles of accumulated PRO were plotted against the incubation time. The data points represent the means \pm SEM ( 2 or 3 batches of cells; 6 experimental values for each point). $B$, Concentration dependence of transport. Proline uptake was measured, over a concentration range from 1 to $100 \mu \mathrm{M}$, during a $20 \mathrm{~min}$ incubation time in KRHT buffer at $37^{\circ} \mathrm{C}$. We kept the concentration of radiolabeled PRO (50 nM) constant and adjusted the total concentration to desired values by adding appropriate concentrations of unlabeled PRO. The high-affinity component of PRO uptake was calculated by subtracting the uptake values obtained in the presence of $100 \mu \mathrm{M}$ GGFL from total uptake measured in the absence of GGFL. We have plotted the PRO uptake rate versus PRO concentration. The data points represent the means \pm SEM as in $A$. The data were analyzed first by nonlinear curve fitting, with the Hill coefficient as a free parameter. After determining that the coefficient was close to one, we set it exactly to one and determined $V_{\max }$ and $K_{\mathrm{m}}$. Proline uptake follows saturable kinetics, with $K_{\mathrm{m}}=20.12 \pm 3.14 \mu \mathrm{M}$ and $V_{\max }=892.26 \pm 39.03 \mathrm{pmol} / 10^{5}$ cells per 10 min. $C$, Eadie-Hofstee plot. The data used in $B$ are plotted as PRO uptake rate, $V$, versus $V /[S]$. These data were fit by linear regression to a line with $V_{\max }\left(y\right.$-intercept) of $816.3 \mathrm{pmol} / 10^{5}$ cells per $10 \mathrm{~min}$ and $K_{\mathrm{m}}(-$ slope $)$ of $20.7 \mu \mathrm{M}$.

dependence of $\left[{ }^{3} \mathrm{H}\right]-\mathrm{PRO}$ uptake on $\mathrm{Na}$ and $\mathrm{Cl}$ concentration are presented in Figure 3, $A$ and $B$. Specific uptake by HP-21 cells increased with Na concentration in a sigmoidal manner, with an apparent $K_{\mathrm{m}}=40.7 \pm 1.7 \mathrm{~mm}$. In contrast, the relationship between specific uptake and $\mathrm{Cl}$ concentration was hyperbolic, 


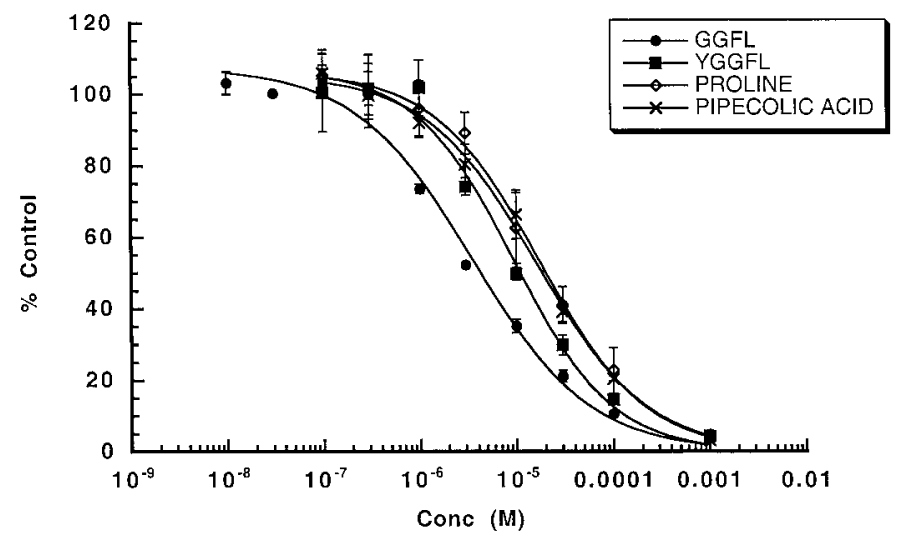

Figure 2. Inhibitor sensitivity of proline uptake in HP-21 cells. Inhibitor potencies were estimated in $\left.50 \mathrm{nM} \mathrm{[}{ }^{3} \mathrm{H}\right]-\mathrm{PRO}$ in standard transport assays that were conducted with various concentrations (in moles per liter) of transport inhibitors and/or substrate. The data are expressed as a percentage of PRO accumulated in the absence of antagonist. The data were fit to a two-parameter expression: the percentage of PRO transport remaining is equal to $100 /\left(1+\left(\mathrm{IC}_{50} /[I]\right)^{n}\right)$, where $\mathrm{IC}_{50}$ is the concentration of competitor giving $50 \%$ of inhibition, $[I]$ is the inhibitor concentration, and $n$ is the Hill coefficient. $\mathrm{IC}_{50}$ values were converted to $K_{\mathrm{i}}$ values by using the Cheng and Prusoff (1973) correction for substrate concentration. Using this analysis, we calculated the following $K_{\mathrm{i}}$ values (in $\mu \mathrm{M}$ ): GGFL, 3.51; YGGFL, 9.44; proline, 16.1; pipecolic acid, 17.44. These data are the average \pm SEM of two experiments performed in triplicate.

with an apparent $K_{\mathrm{m}}=7 \pm 1 \mathrm{~mm}$. The Hill coefficients for $\mathrm{Na}$ and Cl were set to the values $n=2$ and $n=1$, respectively, after initial nonlinear trials that resulted in values close to these. These data are consistent with a substrate stoichiometry for rPROT of 1 PRO: $2 \mathrm{Na}: 1 \mathrm{Cl}$ and a net transfer of one elementary charge per transport cycle at physiological $\mathrm{pH}$.

\section{Proline induces a GGFL-sensitive current in HP-21 cells}

Figure 4 shows data from a HP-21 cell in the whole-cell voltageclamp mode. The holding potential was $-40 \mathrm{mV}$ and the test potential was $-140 \mathrm{mV}$ for $500 \mathrm{msec}$. The raw data were obtained at room temperature and are neither leak-subtracted nor capacity-compensated. PRO (40 $\mu \mathrm{M})$ had no effect on parental cells. These data demonstrate that PRO increases the steady-state component of the current and that GGFL blocks this induced current to control levels. PRO-induced current is defined as the current in the presence of PRO minus the current without PRO (control: Cont). The inset shows the effect of $40 \mu \mathrm{M}$ PIP at -120 $\mathrm{mV}$. GGFL blocks PIP-induced current with equal effectiveness $(n=4)$. GGFL has no effect on the pre-steady-state control current, and, similarly, control-proline curves show no presteady-state effects. Instead, the apparent difference between the on and the off transients represents similar activation/relaxation kinetics of the steady-state currents. Interestingly, two molecules that previously were shown to inhibit PRO uptake in PROTtransfected HeLa cells, L-norleucine and sarcosine (Fremeau et al., 1992; Shafqat et al., 1995), also were able to generate GGFLsensitive inward current at negative voltages (100 $\mu \mathrm{M}$ bath substrate concentration; data not shown). These data support the conclusion that PROT-mediated PRO uptake is electrogenic. Because PRO, PIP, L-norleucine, and sarcosine are able to induce similar currents through the proline transporter, we suggest that these substrates have a similar mechanism of action and a common permeation pathway. On the other hand, the competitive
A

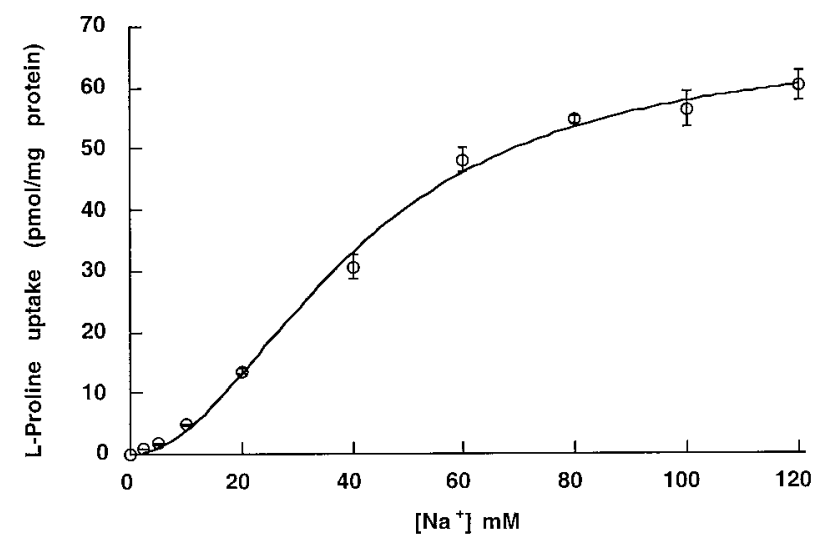

B

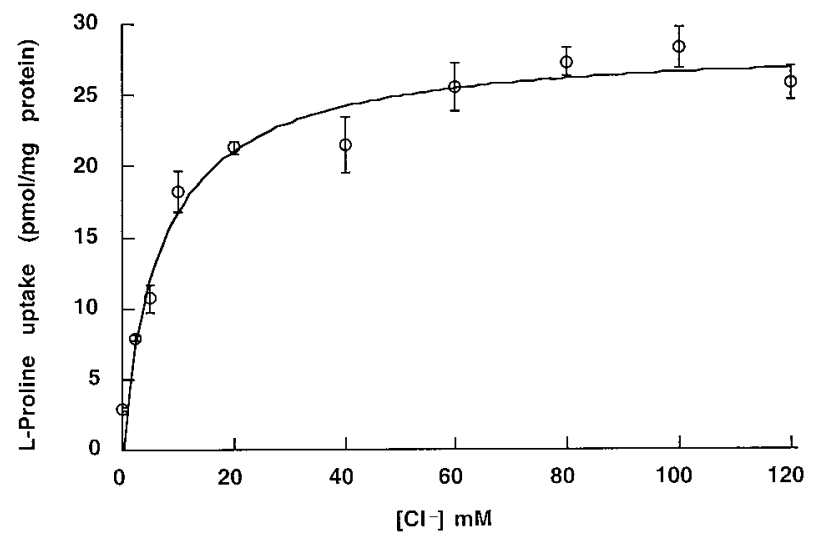

Figure 3. $\mathrm{Na}$ and $\mathrm{Cl}$ concentration dependence of proline uptake in HP-21 cells. Transport rates were measured by using a 10 min incubation as described in Materials and Methods. The standard assay buffer was modified by replacing $\mathrm{NaCl}$ with $\mathrm{LiCl}$ or $\mathrm{Na}$-isethionate to reach the desired $\mathrm{Na}$ or $\mathrm{Cl}$ concentration. For each $\mathrm{Na}$ or $\mathrm{Cl}$ concentration the uptake measured into nontransfected HEK cells was taken as background. $A$, External [Na] was varied, and the data were fit to: $V=V_{\max }$ $[\mathrm{Na}] n /\left(K_{\mathrm{m}}{ }^{n}+[\mathrm{Na}]^{n}\right)$. The data were analyzed first by nonlinear curve fitting, with the Hill coefficient as a free parameter. After determining that the coefficient was close to two, we set it exactly to two and determined $V_{\max }$ and $K_{\mathrm{m}}$. Holding at $n=2, V_{\max }=67.41 \pm 4.49 \mathrm{pmol} / \mathrm{mg}$ protein and $K_{\mathrm{m}}=40.7 \pm 1.7 \mathrm{~mm}$. $B$, External [Cl] was varied, and the data were fit as in $A$. The data were analyzed first by nonlinear curve fitting, with the Hill coefficient as a free parameter. After determining that the coefficient was close to one, we set it exactly to one and determined $V_{\max }$ and $K_{\mathrm{m}}$. Holding at $n=1, V_{\max }=28.46 \pm 1.12 \mathrm{pmol} / \mathrm{mg}$ protein and $K_{\mathrm{m}}=7.0 \pm 1.3 \mathrm{mM}$. The difference in maximal velocities represents a difference in expression level between batches of cells used in the two assays $(n=6)$. Expression levels decrease with increasing passage numbers.

peptide inhibitors GGFL and YGGFL (data not shown for the latter) themselves are unable to induce currents but inhibit substrate-induced currents. These data support the suggestion from previous data that GGFL and YGGFL are nontransported inhibitors of PROT, i.e., antagonists (Fremeau et al., 1996).

\section{$I-V$ curves and mean-variance analysis for proline and L-pipecolate}

Figure 5, $A$ and $B$, compares current-voltage $I-V$ curves for PROand PIP-induced currents obtained from parallel dishes of transfected cells. The $I-V$ relationships were defined by plotting the (background-subtracted) substrate-induced currents against the test voltage. We used concentrations of $\sim 2 \times$ the $K_{\mathrm{m}}$ for uptake, 


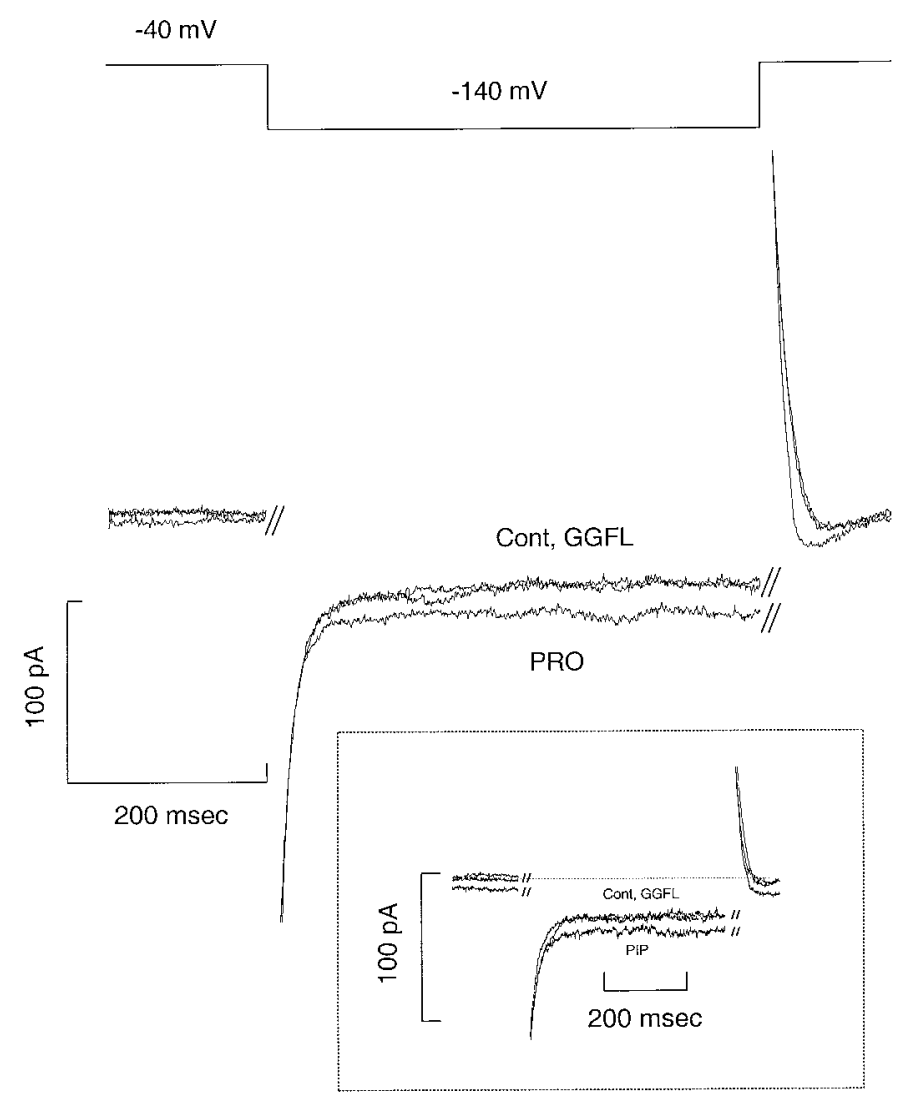

Figure 4. Substrate-induced current in HP-21 cells. Shown is substrateinduced current after bath application of PRO to a voltage-clamped HP-21 cell. The holding potential was $-40 \mathrm{mV}$, and the test potential was $-140 \mathrm{mV}$ for $500 \mathrm{msec}$. After $40 \mu \mathrm{M}$ PRO was added to the bath, the inward current increased at -40 and $-140 \mathrm{mV}$. Substrate-induced current is defined as the difference between the background current (Cont) and PRO-induced inward current. The traces represent raw data without leak subtraction or capacity compensation. The inset shows the inward current induced by bath application of PIP $(40 \mu \mathrm{M})$ at $-120 \mathrm{mV}$. External GGFL was $100 \mu \mathrm{M}$ and was added in the presence of PRO or PIP.

measuring the average substrate-induced current between 400 and 500 msec during the test pulse. The $I-V$ for PRO and PIP are similar in shape and absolute value, providing circumstantial evidence for a mutual mechanism of uptake; however, we have not explored whether PRO and PIP compete for similar binding sites or occlude each other's currents. To investigate whether charge transported through PROTs is uncoupled (Galli et al., 1996, 1997; Larsson et al., 1996; Lester et al., 1996; Sonders and Amara, 1996), we investigated the elementary events that underlie the PRO-induced currents. Figure 5, $C$ and $D$, shows results obtained from current fluctuations induced by PRO and PIP, respectively. Between -140 and $-60 \mathrm{mV}$, the value of $i(1-p)$ for $\mathrm{PRO}$ is $31.4 \pm 17.7 \mathrm{fA}$ and for PIP is $56.4 \pm 48.7 \mathrm{fA}$ (mean \pm $\mathrm{SD})$, with a slope not significantly different from zero for either substrate $(p<0.05)$. Therefore, the $>2 \times$ increase of substrateinduced current observed in the same voltage range does not result from an increase in the elementary current, and there is no statistical correlation between the macroscopic and microscopic current-voltage relations $(r<0.01)$. The subtraction procedure that we used compares the variance with and without PRO or PIP. For this analysis we selected cells that displayed no leak current, i.e., GGFL returned the traces to the control value. Unlike norepinephrine transporters (Galli et al., 1996, 1998), there is no significant difference in control variance or in transient currents in the presence or absence of inhibitor.

\section{The action of GGFL is membrane side-specific}

Although it is evident that GGFL blocks PRO uptake and PROinduced current when added to the outside, it is unclear whether its action, or the action of any transporter antagonist, is sided. To evaluate whether GGFL inhibits PROT at an internal site, we performed experiments in which high concentrations of GGFL were perfused into the cell. When the electrodes were filled with $1 \mathrm{mM}$ GGFL in intracellular buffer, application of $40 \mu \mathrm{M}$ PRO to the bath induced an inward current, as shown in Figure $6 \mathrm{~A}$. Application of external GGFL $(100 \mu \mathrm{M})$ blocked this current. In parallel experiments with dissolved green fluorescent protein (GFP) in the pipette, there was rapid and direct access of the pipette solution to the interior of the cell as observed by fluorescence (data not shown). Nevertheless, to insure that the GGFL entered the cell, we waited 15 min after forming the whole-cell configuration. Externally applied substrate-induced currents were recorded up to $45 \mathrm{~min}$ after the seal was broken. These data support the hypothesis that GGFL binds to an external site that is unavailable from the intracellular compartment. The magnitude and voltage dependence of the (external) GGFL-sensitive PRO-induced current is similar to $I-V$ values obtained in the presence of GGFL in the intracellular compartment (Fig. 6B). Thus GGFL in the cytoplasmic compartment does not affect the ability of the substrate to induce PROT-mediated, voltagedependent inward current.

\section{DISCUSSION}

In vitro flux assays demonstrate that the transport of $\mathrm{PRO}$ into the presynaptic terminals is Na-dependent (Fremeau et al., 1992, 1996). Our uptake data are consistent with a model in which rPROT has a stoichiometry of 1 PRO: $2 \mathrm{Na}$ : $1 \mathrm{Cl}$. The coupling most likely occurs when PRO and the cotransported ions bind the transporter on the external side with an unknown sequence of events. Considering the stoichiometry of the individual transporter events, rPROT would move one elementary charge per transport cycle at physiological pH. Uptake therefore would generate an inward current proportional to the number of transporters present on the cell surface and the rate of transport. Proline transport has been studied previously only with radiolabeled flux assays in which the membrane voltage is not controlled, and we present similar data in the present paper. Electrogenic transport generating inward current mandates depolarization, which with substrate accumulation possibly could inhibit uptake. Thus the shapes of the uptake curves may not reflect entirely the fundamental properties of the transport protein. Moreover, flux assays depend on radiolabeled compounds that are not always available, as in the case of L-pipecolate. We addressed these issues by studying the substrate-induced current with the patch-clamp technique, under the assumption that uptake and current are related. Using the transport-associated current as an indicator of PROT activity, we were able to assay function under defined ionic composition and transmembrane voltage.

We engineered a cell line, HP-21, by stably transfecting HEK293 cells with rPROT cDNA. These cells demonstrate Na- and Cl-dependent PRO uptake that saturates at micromolar concentrations and has a Hill coefficient near 1 for L-proline. GGFL and YGGFL added externally block this transport process. Parallel incubation with unlabeled PRO and PIP demonstrate that both substrates inhibit the transport of radiolabeled L-proline with 

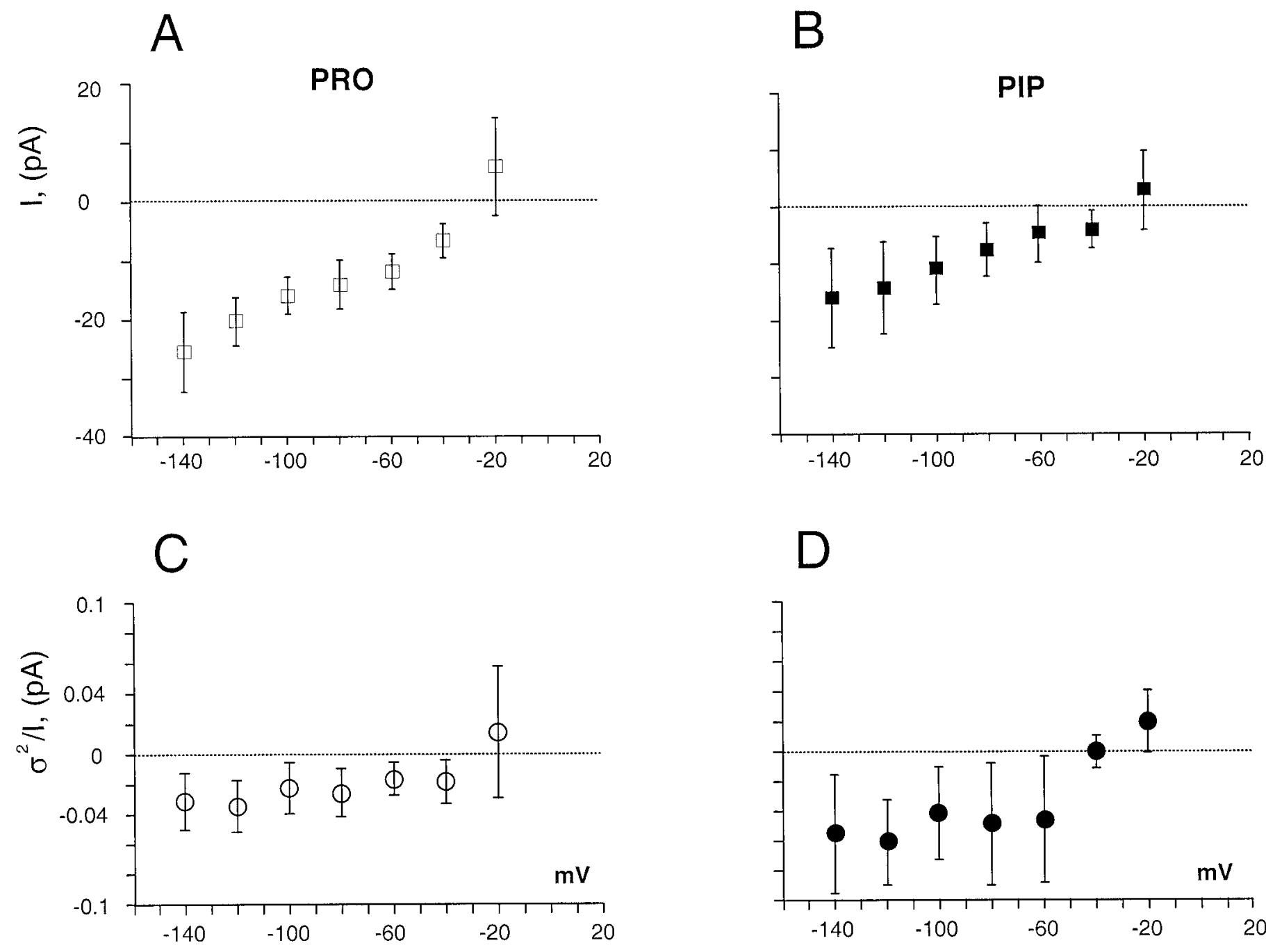

Figure 5. Steady-state $I-V$ curves for PRO- and PIP-induced currents in HP-21 cells. $A$, Steady-state $I-V$ curve for PRO-induced currents was obtained from $500 \mathrm{msec}$ test pulses that ranged from -120 to $-20 \mathrm{mV}$ in $20 \mathrm{mV}$ increments. Substrate concentration was $40 \mu \mathrm{M}$. GGFL blocked substrate-induced currents at concentrations between 100 and $600 \mu \mathrm{M}$. The plot shows that GGFL-sensitive, PRO-induced currents apparently reverse for potentials between -10 and $-30 \mathrm{mV}$. However, there is no significant positive current at any potential. $B$, The steady-state $I-V$ curve for PIP-induced current was obtained by stepping the voltage for $500 \mathrm{msec}$ from -140 to $-20 \mathrm{mV}$, in $20 \mathrm{mV}$ increments, from a $-40 \mathrm{mV}$ holding potential. The substrate concentration was $40 \mu \mathrm{M}$. GGFL blocked the substrate-induced current at concentrations of $100 \mu \mathrm{M}$. The plot shows a GGFL-blocked PIP-induced current, which also apparently reverses between -10 and $-30 \mathrm{mV}$. $C$, The plot shows the difference variance of the PRO-induced current fluctuations, viz., $\sigma^{2}=\sigma_{\text {PRO }}^{2}-\sigma_{\mathrm{CO}}^{2}$, at different voltages. The ratio of the difference variance to the mean steady-state current: $I=I_{\mathrm{PRO}}-I_{\mathrm{CO}}$, was plotted against the voltage. The value of the ratio $\sigma^{2} / I$ is not voltage-dependent. Using this procedure in $40 \mu \mathrm{M}$ PRO, we were able to estimate the magnitude of the underlying events at different voltages. $D$, L-Pipecolate-induced current fluctuations followed the proline pattern. We estimated the increased variance as: $\sigma^{2}=\sigma_{\text {PIP }}^{2}-\sigma_{\text {CO }}^{2}$. An Axopatch 200A band limited with a four-pole Butterworth filter at $2000 \mathrm{~Hz}$ was used to measure currents. The ratio of the variance to the mean current $\left(I=I_{\mathrm{PIP}}-I_{\mathrm{CO}}\right)$ ratio did not show voltage dependence. All data points represent means $\pm \mathrm{SD}(n=4)$.

similar potency. If we assume a stoichiometry of 1 PRO: 2 Na: 1 $\mathrm{Cl}(Q=1)$ and convert a nominal $500 \mathrm{pmol} / 10^{6}$ cells per minute (see Fig. 1) to charges per second, one cell would generate $<1 \mathrm{pA}$ net inward current. In Figure 5, $A$ and $B$, we show that both PRO and PIP induce an inward current of approximately $-5 \mathrm{pA}$ at $-40 \mathrm{mV}$ and $-20 \mathrm{pA}$ at $-140 \mathrm{mV}$. Note, however, that cells are selected individually for high currents and that voltage is clamped at negative potentials, which is likely to promote uptake. In contrast, uptake velocities represent the average from thousands of unclamped cells. These differences between current and uptake measurements may explain the disparity between recorded and calculated current. In any case, it is clear that PROTs contrast markedly with NETs and SERTs, which may generate $100 \times$ the predicted coupled current (Galli et al., 1996, 1997).
At concentrations of $\sim 2 \times$ the $K_{\mathrm{m}}$ for uptake and at $-120 \mathrm{mV}$, PRO or PIP could induce $-20 \mathrm{pA}$ of current. This may be indicative of the previously suggested voltage dependence of the PRO uptake process (Miller et al., 1997a). To test whether the elementary charge transfer changes with voltage, we analyzed the PRO-induced current fluctuations at different potentials. The ratio of variance to mean, $\sigma^{2} / I=i(1-p)$, measures the size of the elementary transport event (Galli et al., 1996). For PROTs this ratio is small (tens of fAs) compared with norepinephrine transporters (hundreds of fAs), and in PROTs the ratio is approximately independent of voltage between -140 and $-60 \mathrm{mV}$. PROT currents apparently reverse at membrane potentials between -10 to $-30 \mathrm{mV}$; however, there is considerable error in measurements near the reversal potential and therefore large 
A

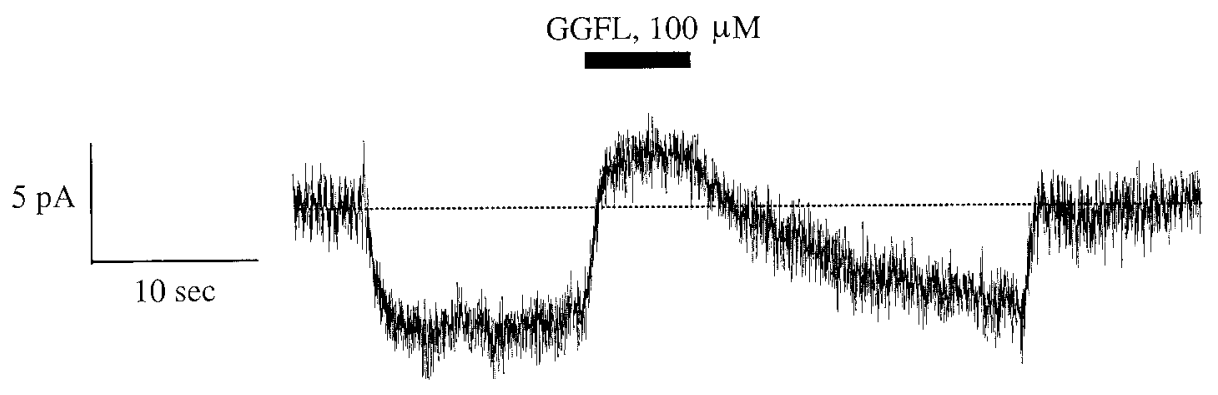

Figure 6. Transporter side-specific block of PRO-induced current by GGFL. $A$, PRO induces an inward current with $1 \mathrm{~mm}$ GGFL in the whole-cell pipette. The application of GGFL (100 $\mu \mathrm{M}$ ) to the bath (extracellular side of the transporter) blocks PRO-induced current. The cell was held at $-40 \mathrm{mV}$. Note the presence of a leak current in these cells, which is observed inconsistently in other cells. $B$, Plotted is the currentvoltage relationship of the substrateinduced current, obtained by using $1 \mathrm{~mm}$ GGFL in the whole-cell pipette. Data are the means \pm SD of six to eight experiments (PRO application and washout under perfusion) from two different cells normalized to the PROinduced current at $-120 \mathrm{mV}$. The shape of the curve suggests saturation at hyperpolarized holding potentials similar to $I-V$ values for PRO and PIP in the absence of internal GGFL $(A, B)$.
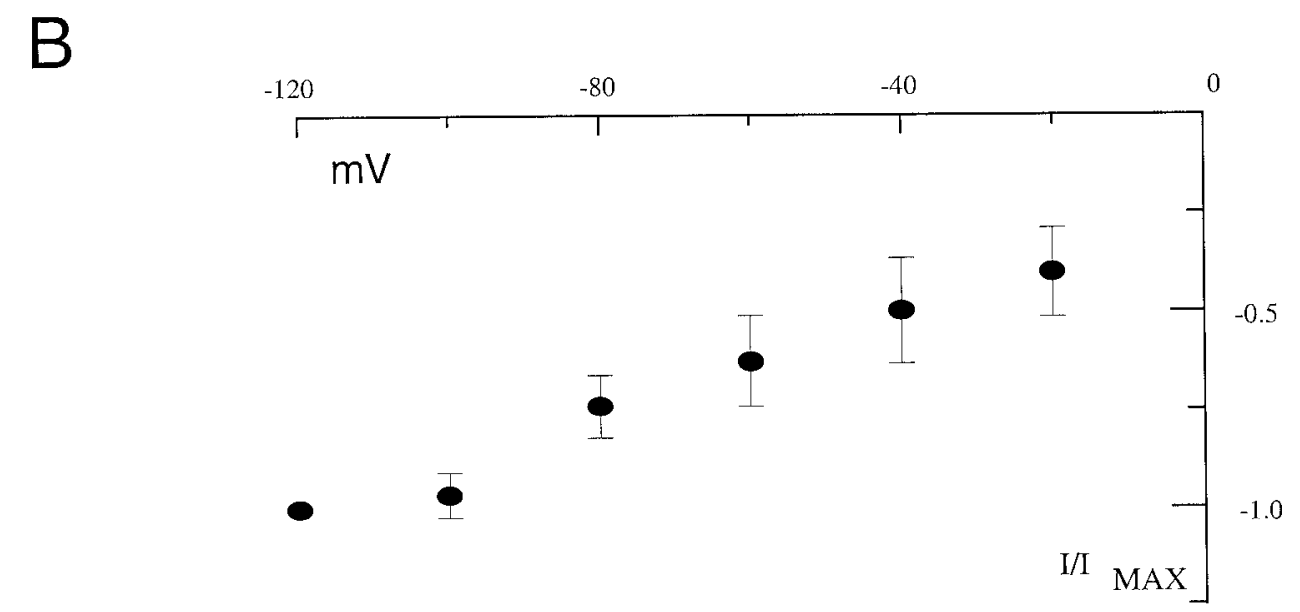

variability in the data. Some cells had a leak current (PROTassociated current as revealed by GGFL in the absence of PRO), whereas other cells did not. Except for these differences, which we attribute to cell-to-cell variation, substrate-induced currents and current fluctuations are similar in PRO or PIP. The variance-mean ratio suggests elementary events of quantal size $i$ $\sim 0.01 \mathrm{pA}$, approximately one-tenth the amplitude of the analogous event in hNET or dSERT (Galli et al., 1996, 1997). The voltage-dependent current likely is related to a voltage-dependent turnover of a coupled transporter rather than voltage-dependent stoichiometry. Moreover, PRO and PIP currents show similar voltage sensitivity at the macroscopic (whole-cell $I-V$ curve) and microscopic (single transporter, $\sigma^{2} / I-V$ curve) levels, consistent with a common mechanism for the action of these two substrates. GGFL and YGGFL block both the transport process and the substrate-induced inward current, but they do not themselves induce a transporter-associated current. These data support the hypothesis that GGFL and YGGFL are nontransported PROT antagonists.

We also obtained data in support of the hypothesis that enkephalin-mediated block of the transporter process is sided. Figure 6 demonstrates that GGFL does not inhibit PRO-induced currents when applied from the inside of the cell, suggesting that the GGFL-binding site faces only the extracellular compartment. This topologically specific inhibition may represent an important physiological interaction between enkephalins and mammalian PROTs (for review, see Fremeau et al., 1996). Enkephalins are stored and released from large dense-cored vesicles in the CNS (Sesack and Pickel, 1992). The concentration of enkephalins in these vesicles is $\sim 1 \mathrm{~mm}$, and, given the geometry of excitatory synapses, the concentration of enkephalin bathing PROTs could be $>10 \mu \mathrm{M}$ (Chen et al., 1995), i.e., near the range that inhibits the proline transporter. Our data show that the peptide fragment GGFL retains the ability to inhibit proline uptake and prolineinduced current. Because enkephalins are degraded by enzymatic hydrolysis generating the des-tyrosyl derivative, we infer that inhibition of proline uptake may persist well after the opioid actions of the enkephalins.

In summary, we have characterized a stable rat PROTexpressing mammalian cell line that is suitable for radiometric and biophysical techniques. Our experiments are consistent with a coupling model of 1 PRO: $2 \mathrm{Na}$ : $1 \mathrm{Cl}$. The magnitude of the substrate-induced current at resting membrane potentials is close to the predicted size of the hypothetical current calculated from $V_{\max }$ values for PRO uptake. Thus, unlike other transporters in this gene family, the proline transporter does not appear to mediate large, uncoupled currents. The putative endogenous substrate, L-proline, and its structurally related congener, L-pipecolate, show similar affinity and efficacy for PROT. Moreover, the level of the substrate-induced current is similar for PRO and PIP, further supporting the hypothesis that these substrates activate PROT by similar mechanisms. This conclusion is sustained by fluctuation analysis of the elementary events associated with the substrate-induced current. We conclude that PROT is electrogenic and that PRO, PIP, L-norleucine, and sarcosine are substrates of PROT. Specifically, we have shown that PIP is either a substrate for the transporter or a rare antagonist of neurotransmitter uptake capable of inducing an inward current. Using the 
patch-clamp technique in whole-cell configuration, we demonstrated that YGGFL and GGFL are transport blockers and identified the side of action of GGFL. Finally, unlike other members of this gene family subject to similar biophysical analysis, rPROT expressed in HEK-293 cells apparently lacks excess uncoupled current. Instead, our results indicate that rPROT behaves as a classical transporter with fixed stoichiometry.

\section{REFERENCES}

Amara SG, Kuhar MJ (1993) Neurotransmitter transporters: recent progress. Annu Rev Neurosci 16:73-93.

Balcar VJ, Johnston GAR, Stephenson AL (1976) Transport of L-proline by rat brain slices. Brain Res 102:143-152.

Bennett JP, Logan WJ, Snyder SH (1972) Amino acid neurotransmitter candidates: sodium-dependent high affinity uptake by unique synaptosomal fractions. Science 178:997-999.

Blakely RD, DeFelice LJ, Hartzell HC (1994) Molecular physiology of norepinephrine and serotonin transporters. J Exp Biol 196:263-281.

Chen L, Gu Y, Huang LY (1995) The mechanism of action for the block of NMDA receptor channels by the opioid peptide dynorphin. J Neurosci 15:4602-4611.

Cheng Y, Prusoff WH (1973) Relationship between the inhibition constant $\left(K_{\mathrm{i}}\right)$ and the concentration of inhibitor which causes 50 percent inhibition $\left(I_{50}\right)$ of an enzymatic reaction. Biochem Pharmacol 22:3099-3108.

Christensen HN (1990) Role of amino acid transport and countertransport in nutrition and metabolism. Physiol Rev 70:43-77.

Clark JA, Amara SG (1994) Stable expression of a neuronal gammaaminobutyric acid transporter, GAT-3, in mammalian cells demonstrates unique pharmacological properties and ion dependence. Mol Pharmacol 46:550-557.

Cohen SM, Nadler JV (1997) Proline-induced potentiation of glutamate transmission. Brain Res 761:271-282.

Crump FT, Fremeau Jr RT, Craig AM (1999) Brain-specific, highaffinity L-proline transporter: preferential localization to a subset of excitatory nerve terminals in cultured rat hippocampal neurons. Mol Cell Neurosci 13:25-29.

Fremeau RT, Caron MG, Blakely RD (1992) Molecular cloning and expression of a high-affinity PRO transporter expressed in putative glutamatergic pathways of rat brain. Neuron 8:915-926.

Fremeau RT, Velaz-Faircloth M, Miller JW, Henzi VA, Cohen SM, Nadler JV, Shafqat S, Blakely RD, Domin B (1996) A novel nonopioid action of enkephalins: competitive inhibition of the mammalian brain high-affinity L-proline transporter. Mol Pharmacol 49:1-9.

Galli A, Blakely R, DeFelice LJ (1996) Norepinephrine transporters have channel modes of conduction. Proc Natl Acad Sci USA 93:8671-8676.

Galli A, Petersen CI, deBlaquiere M, Blakely RD, DeFelice LJ (1997) Drosophila serotonin transporters have voltage-dependent uptake coupled to a serotonin-gated ion channel. J Neurosci 17:3401-3411.

Galli A, Blakely RD, DeFelice LJ (1998) Patch-clamp and amperometric recordings from norepinephrine transporters: channel activity and voltage-dependent uptake [see comments, Proc Natl Acad Sci USA 95:12737-12738]. Proc Natl Acad Sci USA 95:13260-13265.

Giacobini E, Nomura Y, Schmidt-Glenewinkel T (1980) Pipecolic acid: origin, biosynthesis, and metabolism in the brain. Cell Mol Biol 26:135-146.

Kanner BI (1989) Ion-coupled neurotransmitter transport. Curr Opin Cell Biol 1:735-738.

Larson HP, Picaud SA, Werblin FS, Lecar H (1996) Noise analysis of the glutamate-activated current in photoreceptors. Biophys $\mathrm{J}$ 70:733-742.

Lester HA, Mager S, Quick MW, Corey JL (1994) Permeation properties of neurotransmitter transporters. Annu Rev Pharmacol Toxicol 34:219-249.

Lester HA, Cao Y, Mager S (1996) Listening to neurotransmitter transporters. Neuron 17:807-810.

Miller JW, Kleven DT, Domin BA, Fremeau Jr RT (1997a) Cloned sodium- (and chloride-) dependent high-affinity transporter for GABA, glycine, proline, taurine, and creatine. In: Neurotransmitter transporters (Reith MEA, ed), pp 101-150. Totowa, NJ: Humana.

Miller JW, Modjarrad K, Fremeau Jr RT (1997b) Transport properties of the high-affinity L-proline transporter (PROT) determined in membrane vesicles with rPROT cDNA. Soc Neurosci Abstr 23:135.

Nadler JV (1987) Sodium-dependent proline uptake in the rat hippocampal formation: association with ipsilateral commissural projections of CA3 pyramidal cells. J Neurochem 49:1155-1160.

Peterson NA, Raghupathy E (1972) Characteristics of amino acid accumulation of synaptosomal particles isolated from rat brain. J Neurochem 19:1423-1438.

Renick S, Kleven D, Chan J, Stenius K, Milner TA, Pickel VM, Fremeau Jr RT (1999) The mammalian brain, high-affinity L-proline transporter is preferentially enriched in synaptic vesicles in a subpopulation of excitatory nerve terminals in rat forebrain. J Neurosci 19:21-33.

Risso S, DeFelice LJ, Blakely RD (1996) Sodium-dependent GABAinduced currents in GAT1-transfected HeLa cells [comment]. J Physiol (Lond) 490:691-702.

Rudnick G, Clark J (1993) From synapse to vesicle: the reuptake and storage of biogenic amine neurotransmitters. Biochim Biophys Acta 1144:249-263.

Sesack SR, Pickel VM (1992) Dual ultrastructural localization of enkephalin and tyrosine hydroxylase immunoreactivity in the rat ventral tegmental area: multiple substrates for opiate-dopamine interactions. J Neurosci 12:1335-1350.

Shafqat S, Velaz-Faircloth M, Guadano-Ferraz A, Fremeau RT (1993) Molecular characterization of neurotransmitter transporters. Mol Endocrinol 7:1517-1529.

Shafqat S, Velaz-Faircloth M, Henzi VA, Whitney KD, Yang-Feng T, Seldin MF, Fremeau RT (1995) Human brain-specific L-proline transporter: molecular cloning, functional expression, and chromosomal localization of the gene in human and mouse genomes. Mol Pharmacol 48:219-229.

Sonders M, Amara SG (1996) Channels in transporters. Curr Opin Neurobiol 6:294-302.

Stevens BR, Kaunitz JD, Wright EM (1984) Intestinal transport of amino acids and sugars: advances using membrane vesicles. Annu Rev Physiol 46:417-433.

Velaz-Faircloth M, Guadano-Ferraz A, Henzi VA, Fremeau RT (1995) Mammalian brain-specific L-proline transporter. Neuronal localization of mRNA and enrichment of transporter protein in synaptic plasma membranes. J Biol Chem 270:15755-15761. 